\title{
Robust Adaptive Wavelet-Neural-Network Sliding-Mode Speed Control for a DSP-Based PMSM Drive System
}

\author{
Fayez F. M. El-Sousy ${ }^{\dagger}$ \\ $\dagger$ Department of Electrical Engineering, College of Engineering, Al-Kharj University, Saudi Arabia
}

\begin{abstract}
In this paper, an intelligent sliding-mode speed controller for achieving favorable decoupling control and high precision speed tracking performance of permanent-magnet synchronous motor (PMSM) drives is proposed. The intelligent controller consists of a sliding-mode controller (SMC) in the speed feed-back loop in addition to an on-line trained wavelet-neural-network controller (WNNC) connected in parallel with the SMC to construct a robust wavelet-neural-network controller (RWNNC). The RWNNC combines the merits of a SMC with the robust characteristics and a WNNC, which combines artificial neural networks for their online learning ability and wavelet decomposition for its identification ability. Theoretical analyses of both SMC and WNNC speed controllers are developed. The WNN is utilized to predict the uncertain system dynamics to relax the requirement of uncertainty bound in the design of a SMC. A computer simulation is developed to demonstrate the effectiveness of the proposed intelligent sliding mode speed controller. An experimental system is established to verify the effectiveness of the proposed control system. All of the control algorithms are implemented on a TMS320C31 DSP-based control computer. The simulated and experimental results confirm that the proposed RWNNC grants robust performance and precise response regardless of load disturbances and PMSM parameter uncertainties.
\end{abstract}

Key Words: Adaptive control, CRPWM inverter, Field-oriented control, Permanent-magnet synchronous motor (PMSM), Slidingmode control (SMC), Wavelet-neural-network (WNN)

\section{INTRODUCTION}

In recent years, advancements in magnetic materials, semiconductor power devices and control theories have made permanent-magnet synchronous motor (PMSM) drives play a vitally important role in motion-control applications. PMSMs are widely used in high-performance applications such as industrial robots and machine tools because of their compact size, high-power density, high air-gap flux density, hightorque/inertia ratio, high torque capability, high efficiency and because they are maintenance free. The overall performance of the speed control for PMSM drives depend not only on the quickness and the precision of the system response, but also on the robustness of the control strategy. The online variations of parameters, which essentially depend on temperature variations, saturation and skin effects, can heavily affect PMSM drive performances [1]-[6]. In recent years, slidingmode control (SMC) has received a lot of attention in the control of PMSM drives because it can offer beneficial properties such as insensitivity to parameter variations, external load disturbance rejection and fast dynamic response [7]. An

Manuscript received Mar. 18, 2009; revised Jul. 14, 2010

† Corresponding Author: fayes.fm@ksu.edu.sa, fayez@eri.sci.eg Tel: +966-1-5453845, Al-Kharj University

Department of Electrical Engineering, College of Engineering, Al-Kharj

University, Saudi Arabia attribute of the SMC system is that the controller is switched between two distinct control structures, the reaching phase and the sliding phase. To maintain robustness in the whole sliding-mode control system, several researchers have focused on eliminating the effect of the reaching phase [8]-[12]. A sliding curve, chosen as close as possible to the time-optimal trajectory, was proposed in [13],[14] to maintain robustness from the initial point to the final point. However, the system dynamics are still subject to parameters uncertainties. To solve this problem, a WNNC controller is added to the SMC to construct a new robust speed controller for PMSM drives.

In the past several years, a great deal of research has been carried out on neural network control. It has been proven that an artificial neural network can approximate a wide range of nonlinear functions to any desired degree of accuracy under certain conditions. In the conventional gradient descent method of weight adaptation, the sensitivity of the controlled system is required in the on-line training process [15]-[24]. However, it is difficult to acquire sensitivity information for unknown or highly non-linear dynamics. Wavelets have been combined with neural networks to create wavelet-neuralnetworks (WNNs). They combine the capability of artificial neural networks for learning from processes and the capability of wavelet decomposition for identification and control of dynamic systems. The training algorithms for a WNN typically 
converge on a smaller number of iterations than conventional neural networks. Unlike the sigmoid functions used in conventional neural networks, the second layer of a WNN is a wavelet form, in which the translation and dilation parameters are included. Thus, WNNs have been proven to be better than the other neural networks in that their structure can provide a greater potential to enrich the mapping relationship between inputs and outputs [25]-[33].

This paper is organized as follows. Section II presents the FOC and the dynamics of a PMSM drive system. In section III, the problem formulation and a description of the robust wavelet-neural-network sliding-mode speed control for PMSM drives are introduced. The design methodology for the SMC controller is also given. The design procedures and the adaptive learning algorithms of the proposed adaptive WNN control system are described in details in this section. The validity of the design procedure and the robustness of the proposed controller is verified by means of computer simulations and experimental analyses. All of the control algorithms have been developed on a control computer that is based on a TMS320C31 and TMS320P14 DSP DS1102 control board. The dynamic performance of the PMSM drive system has been studied under load changes and parameter uncertainties. Numerical simulations and experimental results are provided to validate the effectiveness of the proposed control system in Section IV. Conclusions are introduced in Section V.

\section{Field-Orientation Control And Dynamics of THE PMSM DRIVE SYSTEM}

Mathematical modeling of the PMSM in the synchronously rotating rotor reference frames is derived in [15]. The stator voltage equations in the $d^{r}-q^{r}$ synchronously rotating rotor reference frame are given by:

$$
\begin{gathered}
V_{q s}^{r}=R_{s} i_{q s}^{r}+L_{s s} \frac{d}{d t} i_{q s}^{r}+\omega_{r} L_{s s} i_{d s}^{r}+\omega_{r} \lambda_{m}^{\prime} \\
V_{d s}^{r}=R_{s} i_{d s}^{r}+L_{s s} \frac{d}{d t} i_{d s}^{r}-\omega_{r} L_{s s} i_{q s}^{r} .
\end{gathered}
$$

The electromagnetic torque can be expressed as:

$$
T_{e}=K_{t} . i_{q s}^{r *}=J_{m}(2 / P) \dot{\omega}_{r}(t)+\beta_{m}(2 / P) \omega_{r}(t)+T_{L} .
$$

The mechanical dynamics of the PMSM drive system can be simplified as:

$$
\dot{\omega}_{r}=A_{m} \omega_{r}+B_{m} \cdot U(t)+D_{m} \cdot T_{L}
$$

where $V_{q s}, V_{d s}, i_{q s}$ and $i_{d s}$ are the stator voltages and currents respectively. $R_{s}$ and $L_{s s}$ are the resistance and the self inductance of the stator. $\omega_{r}, J_{m}, \beta_{m}$ and $P$ are the electrical rotor speed, the effective inertia, the friction coefficient and the number of poles of the motor, respectively. $T_{e}$ and $T_{L}$ are the electromagnetic torque and the load torque, respectively. $\lambda_{m}$, is the flux linkage, the torque constant, $K_{t}=(3 / 2) \cdot(P / 2) \cdot \lambda_{m}$., $U(t)=i_{q s}^{r *}(t)$ is the control effort, $A_{m}=-\left(\beta_{m} / J_{m}\right) \cdot(P / 2)$, $B_{m}=K_{t} /\left(J_{m} \cdot P / 2\right)$ and $D_{m}=-(P / 2) \cdot\left(1 / J_{m}\right) \cdot T_{L}$.

\section{Robust WAVELET-NeURAL-Network SLiding-Mode Control System}

\section{A. Problem Formulation}

In order to efficiently control the rotor speed of the PMSM drive system, a robust wavelet-neural-network sliding-mode controller is proposed to increase the robustness of the FOCPMSM drive system. In [12], a two-degrees-of-freedom integral plus proportional \& rate feedback (2DOF I-PD) speed controller is designed to stabilize the speed control loop. The gains of the 2DOF I-PD speed controller have been determined using the ITAE performance index response method to obtain the desired control performance in the nominal conditions of command tracking. The 2DOF I-PD speed controller parameters and the reference model are given by:

$$
\begin{gathered}
K_{p}^{\omega}=\left(\frac{2.7 \omega_{n}^{3}-K_{m}^{c} \beta_{m} / J_{m}}{K_{m}^{\omega} K_{m}^{c} K_{t}}\right) \\
K_{i}^{\omega}=\frac{\omega_{n}^{4}}{K_{m}^{\omega} K_{m}^{c} K_{t}} \\
K_{d}^{\omega}=\left(\frac{3.4 \omega_{n}^{2}-K_{m}^{c}-\tau_{c} \beta_{m} / J_{m}}{K_{m}^{\omega} K_{m}^{c} K_{t}}\right) \\
G_{r m}^{\omega}(s)=\frac{b_{\circ} K^{\omega}\left(1+\tau_{1} s\right)}{b_{3} s^{3}+b_{2} s^{2}+b_{1} s^{1}+b_{\circ}} .
\end{gathered}
$$

The intelligent sliding-mode speed control system for PMSM drives is shown in Fig. 1. The proposed intelligent speed controller combines a SMC and a WNNC. The adaptive control law is designed as:

$$
\begin{gathered}
U_{q s}^{*}(t)=i_{q s}^{r c}(t)=U_{q s}^{* W N N C}(t)+U_{q s}^{* S M C}(t) \\
i_{q s}^{r c}(t)=\delta i_{q s}^{r * W N N C}(t)+i_{q s}^{r * S M C}(t) .
\end{gathered}
$$

The q-axis current command is generated by the SMC while the adaptive control signal is generated by the proposed WNNC to automatically compensate for the performance degradation due to load disturbances and PMSM parameter uncertainties. The input to the SMC is the speed error, to construct the sliding surface $S(t)$ and the sliding-mode control law to get the q-axis current command. The inputs to the WNNC are the errors between the reference model and the actual rotor speed and the rate of change for this error, along with the rotor speed and the rate of change for the rotor speed. These signals are used to train the connective weights of the WNNC. The output of the WNNC is the adaptive control signal, $\delta i_{q s}^{r *}$.

$$
\begin{gathered}
e_{\omega}^{m f}=\left(\omega_{r}^{m f}-\omega_{r}\right), \dot{e}_{\omega}^{m f}=k_{\omega}^{r m}\left(\dot{\omega}_{r}^{m f}-\dot{\omega}_{r}\right) \\
\dot{\omega}_{r}=k_{\omega} d \omega_{r} / d t, \dot{\omega}_{r}^{r m}=k_{\omega}^{r m} d \omega_{r}^{r m} / d t .
\end{gathered}
$$




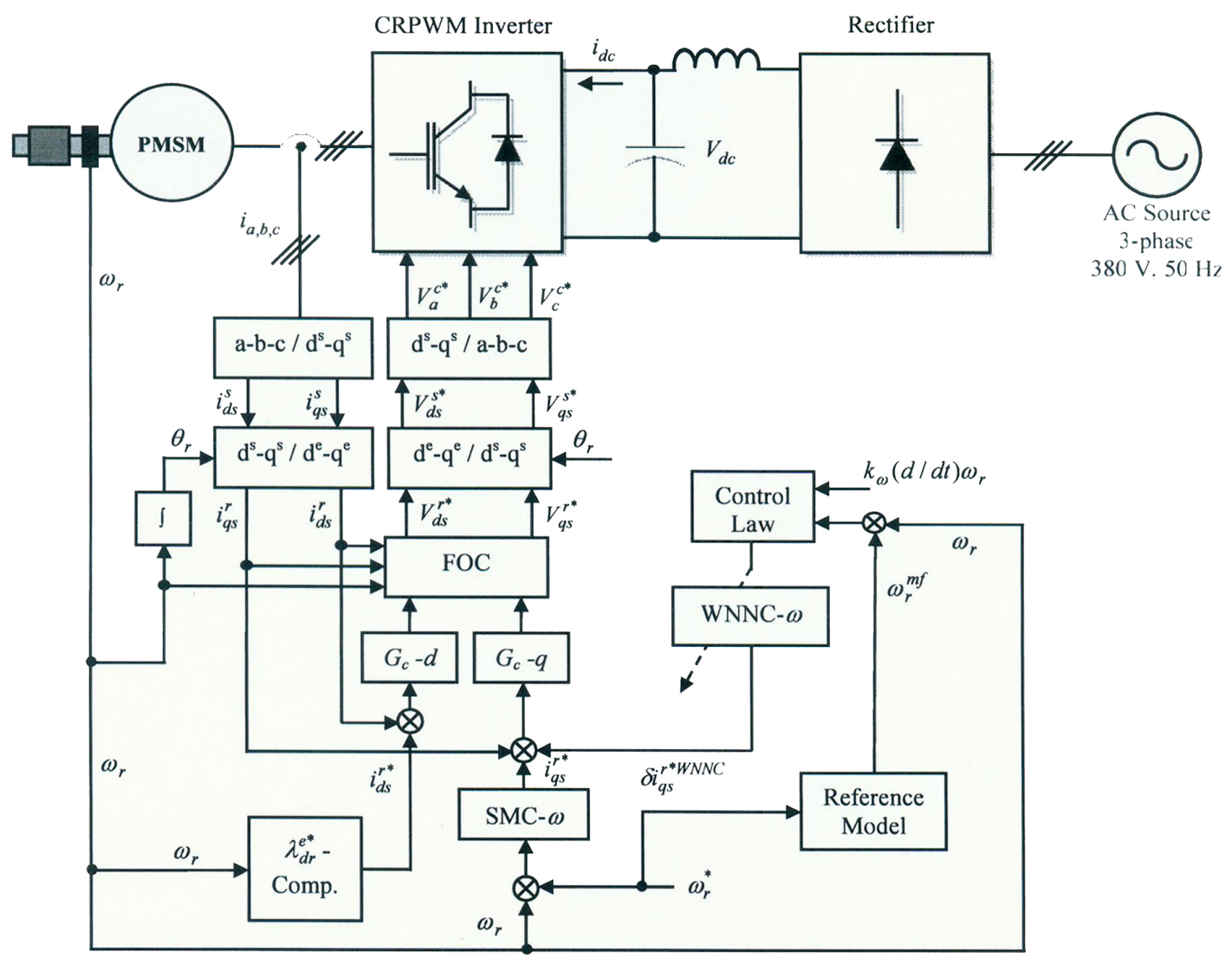

Fig. 1. Integrated block schematic diagram of the proposed intelligent slidingmode control for PMSM drive system.

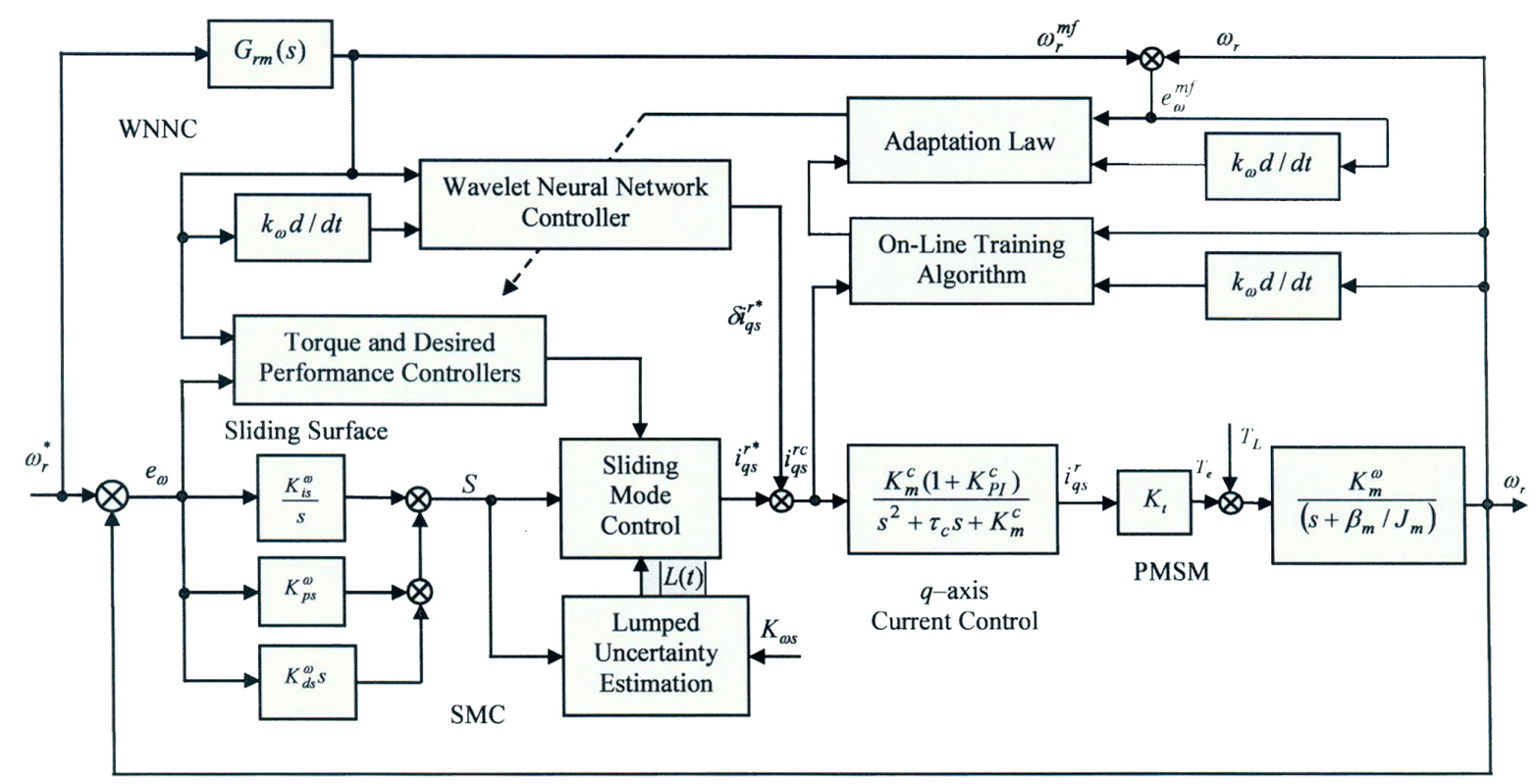

Fig. 2. Structure of the proposed robust waveletneuralnetwork slidingmode control (RWNNC) for PMSM drive system. 


\section{B. Sliding-Mode Speed Controller (SMC)}

The structure of the sliding-mode controller for the PMSM drive system is shown in Fig. 2. By considering the dynamics in (4) along with the parameter variations, the disturbance load and the unpredictable uncertainties the following is obtained:

$$
\begin{aligned}
\dot{\omega}_{r}(t)= & \left(A_{m n}+\Delta A_{m}\right) \omega_{r}(t)+\left(B_{m n}+\Delta B_{m}\right) \cdot U(t) \\
& +\left(D_{m n}+\Delta D_{m}\right) \cdot T_{L} \\
& \dot{\omega}_{r}(t)=A_{m n} \omega_{r}(t)+B_{m n} \cdot U(t)+L(t)
\end{aligned}
$$

where $\Delta A_{m}, \Delta B_{m}$ and $\Delta D_{m}$ are the uncertainties due to the mechanical parameters $J_{m}$ and $\beta_{m}$, and $L(t)$ is the lumped parameter uncertainty, which is defined as:

$$
L(t)=\Delta A_{m} \omega_{r}(t)+\Delta B_{m} \cdot U(t)+\left(D_{m n}+\Delta D_{m}\right) T_{L} .
$$

The bound of the lumped parameter uncertainty is assumed to be $|L(t)| \leq K_{\omega s}$. The objective is to design a control law so that the rotor speed of the PMSM can track any desired command. To achieve this control objective, we can define the error speed function so that $e_{\omega}(t)=\left(\omega_{r}^{*}(t)-\omega_{r}(t)\right)$. The sliding surface can be defined as the proportional plus the integral plus the derivative (PID) performance tracking measure, which is given by:

$$
S(t)=K_{p s} e_{\omega}(t)+K_{d s} \dot{e}_{\omega}(t)+K_{i s} \int e_{\omega}(\tau) d \tau
$$

where the positive constants $K_{p s}, K_{d s}$ and $K_{i s}$ are designed based on the desired drive system dynamics such as the rise time, the overshoot and the settling time. Differentiating $\mathrm{S}(\mathrm{t})$ with respect to time gives:

$$
\dot{S}(t)=K_{p s}\left(\dot{e}_{\omega}(t)+\left(K_{d s} / K_{p s}\right) \ddot{e}_{\omega}(t)+\left(K_{i s} / K_{p s}\right) e_{\omega}(t)\right) .
$$

Using the differentiation of the error speed function, $\dot{e}_{\omega}(t)=\left(\dot{\omega}_{r}^{*}(t)-\dot{\omega}_{r}(t)\right)$, and (14) and substituting into (17) will yield:

$$
\dot{S}(t)=K_{p s}\left(\begin{array}{l}
\dot{\omega}_{r}^{*}(t)-A_{m n} \omega_{r}-B_{m n} U_{q s}^{* S M C} \\
-L(t)+\left(K_{d s} / K_{p s}\right) \ddot{e}_{\omega}(t)+\left(K_{i s} / K_{p s}\right) e_{\omega}(t)
\end{array}\right)
$$

The tracking problem is to find a control law $U_{q s}^{* S M C}$ so that the rotor speed remains on the sliding surface for all $t>0$. In the design of the SMC system, the ideal equivalent control law, which determines the dynamics of the drive system on the switching surface, is derived. The ideal equivalent control law is derived from $\dot{S}(t)=0$. Applying this equality to (18) will yield:

$$
\left(\begin{array}{c}
\dot{\omega}_{r}^{*}(t)-A_{m n} \omega_{r}-B_{m n} U_{q s}^{* S M C}-L(t)+\left(K_{d s} / K_{p s}\right) \ddot{e}_{\omega}(t) \\
+\left(K_{i s} / K_{p s}\right) e_{\omega}(t) \\
=0
\end{array}\right)
$$

From (19) and the lumped parameter uncertainty condition $|L(t)| \leq K_{\omega s}$, the sliding-mode control objective is given by:

$$
\begin{aligned}
& U_{q s}^{* S M C}(t)=i_{q s}^{r *}(t)=B_{m n}^{-1}\left[\dot{\omega}_{r}^{*}(t)-A_{m n} \omega_{r}(t)\right. \\
& \left.+\left(K_{d s} / K_{p s}\right) \ddot{e}_{\omega}(t)+\left(K_{i s} / K_{p s}\right) e_{\omega}(t)-K_{\omega s} \operatorname{sgn}(S(t))\right]
\end{aligned}
$$

The main advantage of the SMC is its insensitivity to parameter variations in the switching surface. To keep the trajectory in the sliding surface, the selection of the control gain, $K_{\omega s}$, is very important due to its significant effect on the magnitude of the lumped parameter uncertainties of the PMSM drive and hence its performance. An incorrect selection of the control gain will yield a deviation in the sliding surface and cause a chattering phenomena. If uncertainties are absent, once the switching surface is reached, a very small positive value of the control gain, $K_{\omega s}$, will be sufficient to keep the trajectory on the sliding surface and as a result the amplitude of the chattering is small. However, when the uncertainties are present, deviations from the sliding surface will occur and cause a great deal of chattering. To solve this problem an adaptive controller using a WNN is augmented to the SMC to preserve the desired tracking response under parameter uncertainties and load disturbances. A bound observer is adopted to predict the control gain, $K_{\omega s}$. Under parameter uncertainties, deviations from the sliding surface will need a continuous prediction of the control gain, $K_{\omega s}$, observed by the bound observer to push the PMSM drive system trajectory back onto the sliding surface. The bound observer is based on the tracking error between the reference model and the actual rotor speed. The control gain is updated such that $K_{\omega s}=K_{\omega s}^{*}+\varepsilon$, where $\epsilon$ is the approximation tracking error. The continuous prediction of the control gain, $\mathrm{K} \omega \mathrm{s}$, will be stopped when the speed tracking error reaches zero.

\section{Wavelet-Neural-Network Speed Controller (WNNC)}

A WNN is introduced for the speed control of a PMSM drive. The nodes in the hidden layers perform as a mother wavelet and a wavelet. A learning algorithm is then used to update the parameters of the WNNC. The supervised gradient descent method, which uses a delta adaptation law, is utilized to train the WNN on-line. The proposed WNNC observes the behavior of the PMSM drive system and compares the actual

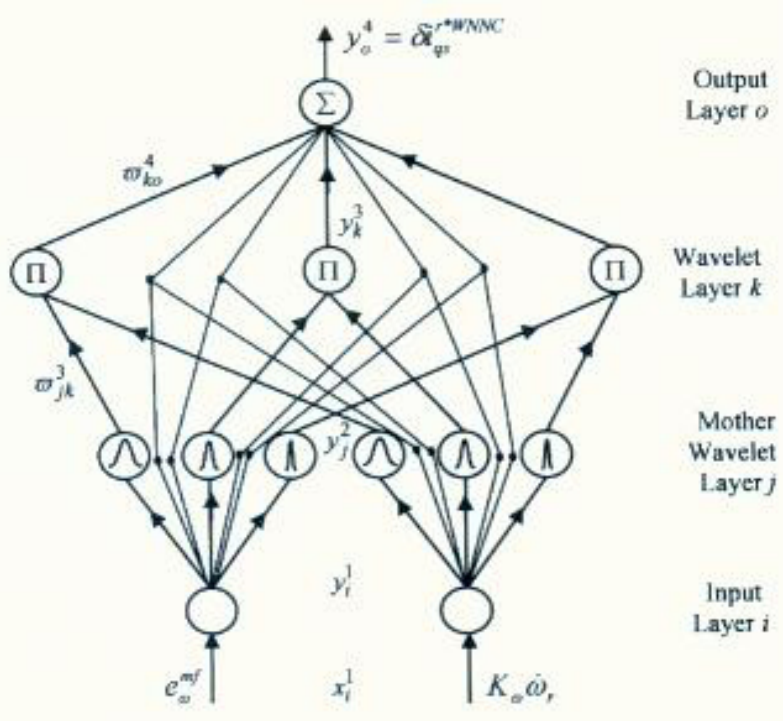

Fig. 3. Four layer wavelet-neural-network structure. 
performance with a desired reference model performance. The learning algorithm modifies the parameters of the WNNC based on a model-following error to match the actual response with the desired reference model response.

\section{Wavelet-Neural-Network Structure}

The architecture of the proposed four-layer WNN, shown in Fig. 3, which comprises an input layer (the $i$ layer), a mother wavelet layer (the $j$ layer), a wavelet layer (the $k$ layer) and an output layer (the $o$ layer), is adopted to implement the WNNC. The signal propagation and the basic function in each layer are introduced as follows:

1) Layer 1: Input Layer: The nodes in layer 1 transmit the input signals to the next layer. The input variables are the error signal, $e_{\omega}^{m f}$, and the rate of change of the rotor speed, $K_{\omega} \dot{\omega}_{r}$. For every node $\mathrm{i}$ in the input layer, the input and the output of the WNN can be represented as:

$$
\begin{gathered}
\text { net }_{i}^{1}=x_{i}^{1}, y_{i}^{1}=f_{i}^{1}\left(\text { net }_{i}^{1}\right)=\text { net }_{i}^{1} \quad i=1,2 \\
x_{1}^{1}=e_{\omega}^{m f}(t) \text { and } x_{2}^{1}=K_{\omega} \dot{\omega}_{r}(t) .
\end{gathered}
$$

2) Layer 2: Mother Wavelet Layer: A family of wavelets is constructed by translations and dilations performed on the mother wavelet. In the mother wavelet layer each node performs a wavelet $\phi_{j}$ that is derived from its mother wavelet. There are many kind of wavelets that can be used in a WNN. In this paper, the first derivative of the Gaussian wavelet function $\phi(x)=-x \exp \left(-x^{2} / 2\right)$, is adopted as a mother wavelet. For the $j$ th node:

$n e t_{j}^{2}=-\frac{x_{i}^{2}-\mu_{i j}}{\sigma_{i j}}, y_{j}^{2}=f_{j}^{2}\left(\right.$ net $\left._{j}^{2}\right)=\phi_{j}\left(\right.$ net $\left._{j}^{2}\right) \quad j=1, \ldots, n$

where $\mu_{i j}$ and $\sigma_{i j}$ are the translations and dilations in the $j$ th term of the $i$ th input $x_{i}^{2}$ to the node of the mother wavelet layer and $\mathrm{n}$ is the total number of wavelets with respect to the input nodes.

3) Layer 3: Wavelet Layer: Each node $k$ in layer 3 (wavelet layer) is denoted by $\prod$, which multiplies the incoming signals and outputs the results of the product. For the $k$ th nodes:

$n e t_{k}^{3}=\prod_{j} \varpi_{j k}^{3} x_{j}^{3}, y_{k}^{3}=f_{k}^{3}\left(n e t_{k}^{3}\right)=\operatorname{net}_{k}^{3} \quad k=1, \ldots \ldots \ldots, m$

where $x_{j}^{3}$ represents the $j$ th input to the node of the wavelet layer (layer 3), $\varpi_{j k}^{3}$ is the weight between the mother wavelet layer and the wavelet layer. This weight is also assumed to be unity; and $m=(n / i)$ is the number of wavelets if each input node has the same mother wavelet nodes.

4) Layer 4: Output Layer: The single node o in the output layer is denoted by $\Sigma$, which computes the overall output as the summation of all incoming signals to obtain the final results.

$$
\begin{gathered}
n e t_{o}^{4}=\sum_{k}^{m} \varpi_{k o}^{4} x_{k}^{4}, y_{o}^{4}=f_{o}^{4}\left(\text { net }_{o}^{4}\right)=\text { net }_{o}^{4} \quad o=1 \\
y_{o}^{4}=U_{q s}^{* W N N C}(t)=\delta i_{q s}^{r * W N N C}(t)
\end{gathered}
$$

where the connecting weight $\varpi_{k o}^{4}$ is the output action strength of the oth output associated with the $k$ th wavelet and $x_{k}^{4}$ represents the $k$ th input to the node of output layer. The vectors $\sigma$ and $\mu$ collecting all of the parameters of the hidden layer in the WNN are defined as:

$$
\begin{gathered}
\sigma=\left[\sigma_{11} \ldots \sigma_{n 1}, \sigma_{12} \ldots \sigma_{n 2}, \sigma_{1 n} \ldots \sigma_{m n}\right] \\
\mu=\left[\mu_{11} \ldots \mu_{n 1}, \mu_{12} \ldots \mu_{n 2}, \mu_{1 n} \ldots \mu_{m n}\right] \\
y_{o}^{4}(x, \sigma, \mu, \varpi)=\varpi^{T} \Phi(x, \sigma, \mu) .
\end{gathered}
$$

where $x=\left[x_{1}^{1}, x_{2}^{1}\right]^{T}, \varpi=\left[\varpi_{1 o}, \varpi_{2 o}, \ldots \ldots . ., \varpi_{n o}\right]^{T}$ and $\Phi=$ $\left[\Phi_{1}, \Phi_{2}, \ldots \ldots . ., \Phi_{m}\right]^{T}=\left[x_{1}^{4}, x_{2}^{4}, \ldots \ldots \ldots, x_{m}^{4}\right]^{T}$.

The control problem is to design the WNNC to improve the convergence of the tracking error for the PMSM drive system.

\section{E. On-Line Training Algorithm Signal Analysis for a WNNC}

The essential part of the learning algorithm for a WNN concerns how to obtain a gradient vector in which each element in the learning algorithm is defined as a derivative of the energy function with respect to a parameter of the network using the chain rule. Since the gradient vector is calculated in the direction opposite to the flow of the output of each node, the method is generally referred to as the backpropagation learning rule [25]-[33]. To describe the on-line learning algorithm of the WNNC using the supervised gradient descent method, the energy function is chosen as:

$$
E_{\omega}=\frac{1}{2}\left(\omega_{r}^{m f}-\omega_{r}\right)^{2}=\frac{1}{2}\left(e_{\omega}^{m f}\right)^{2} .
$$

In the output layer (layer 4), the error term to be propagated is calculated as:

$$
\delta_{o}^{4}=-\frac{\partial E_{\omega}}{\partial y_{o}^{4}}=-\frac{\partial E_{\omega}}{\partial e_{\omega}^{m f}} \cdot \frac{\partial e_{\omega}^{m f}}{\partial n e t_{o}^{4}}=-\frac{\partial E_{\omega}}{\partial e_{\omega}^{m f}} \cdot \frac{\partial e_{\omega}^{m f}}{\partial \omega_{r}} \cdot \frac{\partial \omega_{r}}{\partial n e t_{o}^{4}} .
$$

The weight is updated by the amount:

$\Delta \varpi_{k o}^{4}=-\eta_{\omega} \frac{\partial E_{\omega}}{\partial \varpi_{k o}^{4}}=\left[-\eta_{\omega} \frac{\partial E_{\omega}}{\partial y_{o}^{4}} \cdot \frac{\partial y_{o}^{4}}{\partial n e t_{o}^{4}}\right] \cdot \frac{\partial n e t_{o}^{4}}{\partial \varpi_{k o}^{4}}=\eta_{\omega} \delta_{o}^{4} x_{k}^{4}$

where $\eta_{\omega}$ is the learning rate parameter of the connecting weights of the output layer of the WNNC.

The weights of the output layer (layer 4) are updated according to the following equation:

$$
\varpi_{k o}^{4}(N+1)=\varpi_{k o}^{4}(N)+\Delta \varpi_{k o}^{4}=\varpi_{k o}^{4}(N)+\eta_{\omega} \delta_{o}^{4} x_{k}^{4}
$$

where $N$ denotes the number of iterations.

In the wavelet layer (layer 3), only the error term needs to be computed and propagated because the weights in this layer are unity.

$\delta_{k}^{3}=-\frac{\partial E_{\omega}}{\partial n e t_{k}^{3}}=\left(-\frac{\partial E_{\omega}}{\partial y_{o}^{4}} \cdot \frac{\partial y_{o}^{4}}{\partial n e t_{o}^{4}}\right) \cdot\left(\frac{\partial n e t_{o}^{4}}{\partial y_{k}^{3}} \cdot \frac{\partial y_{k}^{3}}{\partial n e t_{k}^{3}}\right)=\delta_{o}^{4} \varpi_{k o}^{4}$.

In the mother wavelet layer (layer 2), the multiplication operation is done. The error term is calculated as follows:

$$
\begin{aligned}
\delta_{j}^{2}=- & \frac{\partial E_{\omega}}{\partial n e t_{j}^{2}}=\left(-\frac{\partial E_{\omega}}{\partial y_{o}^{4}} \cdot \frac{\partial y_{o}^{4}}{\partial n e t_{o}^{4}} \cdot \frac{\partial n e t_{o}^{4}}{\partial y_{k}^{3}} \cdot \frac{\partial y_{k}^{3}}{\partial n e t_{k}^{3}}\right) \\
& \cdot\left(\frac{\partial n e t_{k}^{3}}{\partial y_{j}^{2}} \cdot \frac{\partial y_{j}^{2}}{\partial n e t_{j}^{2}}\right)=\sum_{k} \delta_{k}^{3} y_{k}^{3}
\end{aligned}
$$


The update law of $\mu_{i j}$ is given by:

$$
\begin{aligned}
\Delta \mu_{i j} & =-\eta_{\mu} \frac{\partial E_{\omega}}{\partial \mu_{i j}}=\left[-\eta_{\mu} \frac{\partial E_{\omega}}{\partial y_{j}^{2}} \cdot \frac{\partial y_{j}^{2}}{\partial n e t_{j}^{2}} \cdot \frac{\partial n e t_{j}^{2}}{\partial \mu_{i j}}\right] \\
& =\eta_{\mu} \delta_{j}^{2}\left(\frac{x_{i}^{2}-\mu_{i j}}{\sigma_{i j}}\right) .
\end{aligned}
$$

The update law of $\sigma_{i j}$ is given by:

$$
\begin{aligned}
\Delta \sigma_{i j} & =-\eta_{\sigma} \frac{\partial E_{\omega}}{\partial \sigma_{i j}}=\left[-\eta_{\sigma} \frac{\partial E_{\omega}}{\partial y_{j}^{2}} \cdot \frac{\partial y_{j}^{2}}{\partial n e t_{j}^{2}} \cdot \frac{\partial n e t_{j}^{2}}{\partial \sigma_{i j}}\right] \\
& =\eta_{\sigma} \delta_{j}^{2}\left(\frac{x_{i}^{2}-\mu_{i j}}{\sigma_{i j}}\right) .
\end{aligned}
$$

where $\eta_{\mu}$ and $\eta_{\sigma}$ are the learning rate parameters of the translation and dilation of the mother wavelet. The translation and dilation of the mother wavelet are updated as follows:

$$
\begin{aligned}
& \mu_{i j}(N+1)=\mu_{i j}(N)+\Delta \mu_{i j} \\
& \sigma_{i j}(N+1)=\sigma_{i j}(N)+\Delta \sigma_{i j} .
\end{aligned}
$$

To overcome the problem of uncertainties in the PMSM due to parameter variations and to increase the on-line learning rate of the network parameters, a control law is proposed as follows:

$$
\delta_{o}^{4}=e_{\omega}^{m f}+K_{\omega} \dot{\omega}_{r}
$$

\section{Numerical Simulations AND Experimental RESULTS}

To investigate the effectiveness of the proposed SMC and RWNNC control schemes, a simulation is carried out using the Matlab/Simulink package based on the scheme shown in Fig. 1. In order to demonstrate the control performance of the PMSM drive system, the simulation results due to periodic commands are given. A block diagram of the DSPbased control system for field-oriented control of a PMSM drive system is shown in Fig. 4. The proposed WNN-SMC control, the field-oriented control, the space vector pulse width modulation (SVPWM), the coordinate transformations and the point-to-point speed control have been developed in Matlab/Simulink on a control computer that is based on a TMS320C31 DSP board 1102 from dSPACE to build a fully digital PMSM drive system. The control board dSPACE 1102 includes multi-channels of ADC, DAC, PIO and an encoder interface. The current-regulated PWM VSI is implemented using an intelligent power module (IPM) switching component. A digital filter and a frequency multiplied by four circuits are built into the encoder interface circuits to increase the precision of the speed feedback and the position of the coordinate transformations.

\section{A. Numerical Simulation of the addressStreetPMSM Drive System}

The simulations results of the PMSM drive system are presented to verify the feasibility of the proposed control scheme under various operating conditions. The dynamic performance of the drive system due to a speed command of $377 \mathrm{rad} / \mathrm{sec}$ under a subsequent loading of $3.6 \mathrm{~N} . \mathrm{m}$ is predicted and illustrated in Fig. 4. The disturbance rejection capabilities have been checked when a load of 3.6 N.m is applied to the shaft at $\mathrm{t}=1.5 \mathrm{sec}$ and then removed after a period of $1.5 \mathrm{sec}$.
The simulation results of the proposed SMC and RWNNC are shown in Fig. 5, which includes the command and the actual responses for speed, as well as the d-q axes stator currents in the rotating reference frames for both speed controllers. These Figures clearly illustrate good dynamic performances in the command tracking and the load regulation performance is realized for both controllers. Improvement of the control performance by the addition of the proposed RWNNSMC speed controller can be observed from the obtained results in the command tracking and the load regulation characteristics. The model-following response and the model-following error (MFE) for both of the speed controllers are given in Fig. 5. It is evident that the model-following error (MFE) due to the SMC speed controller reaches to $0.57 \mathrm{rad} / \mathrm{sec}$ while the MFE due to the RWNNC speed controller is about $0.21 \mathrm{rad} / \mathrm{sec}$. The results illustrate the model-following response, the load regulation performance and the tracking errors for both of the speed controllers. It is clear from this Figure that a good model-following response is granted using the RWNNSMC speed controller. It is also clear that the proposed RWNNSMC speed controller provides a rapid and accurate response for the reference model within $0.23 \mathrm{sec}$. Also, the proposed controller quickly returns the speed to the reference under a full load with a maximum dip of $8 \mathrm{rad} / \mathrm{sec}$ while the SMC provides a maximum dip of $12 \mathrm{rad} / \mathrm{sec}$ and a recovery time of $0.30 \mathrm{sec}$.

The robustness of the proposed SMC and RWNNSMC speed controllers against large uncertainties in the PMSM parameters and external load disturbances has been simulated for demonstration. The simulation results of the dynamic response for both speed controllers are plotted in Figs. 6 and 7. To investigate the effectiveness of the proposed SMC and RWNNSMC speed controllers, three cases with parameter uncertainties in the stator resistance, the self inductance, the motor inertia, the flux linkage and the load torque disturbance are considered. The following possible ranges of parameter uncertainties and external disturbances are considered:

Case 1: $1.0 \times\left(R_{s}\right.$ and $\left.L_{s}\right), 1.0 \times\left(J_{m}\right.$ and $\left.\beta_{m}\right), 1.00 \times \lambda_{m}$ Case 2: $0.5 \times\left(R_{s}\right.$ and $\left.L_{s}\right), 0.5 \times\left(J_{m}\right.$ and $\left.\beta_{m}\right), 0.85 \times \lambda_{m}$ Case 3: $1.5 \times\left(R_{s}\right.$ and $\left.L_{s}\right), 4.0 \times\left(J_{m}\right.$ and $\left.\beta_{m}\right), 1.25 \times \lambda_{m}$

The speed response, the tracking errors and the load regulation performance of the drive system with the SMC and RWNNC speed controllers are shown in Figs. 6 and 7 under the three cases of PMSM parameter uncertainties. Fig. 6 illustrates the speed, the q-axis torque current tracking and the tracking errors responses for both of the speed controllers. Under the same conditions, the load regulation performance and the torque current responses are given in Fig. 7. The results shown in Figs. 6 and 7 clearly indicate that as the uncertainties in the PMSM parameters occur, the responses deviate insignificantly from the nominal case with the SMC and RWNNSMC speed controllers, while the RWNNSMC speed controller confirms the correct operation and is slightly influenced by full load conditions under the three cases of PMSM uncertainties. It is also clear from Figs 6 and 7 that the proposed RWNNSMC controller provides a rapid and accurate response for the reference model. Also, the proposed controller quickly returns the rotor speed to the reference 


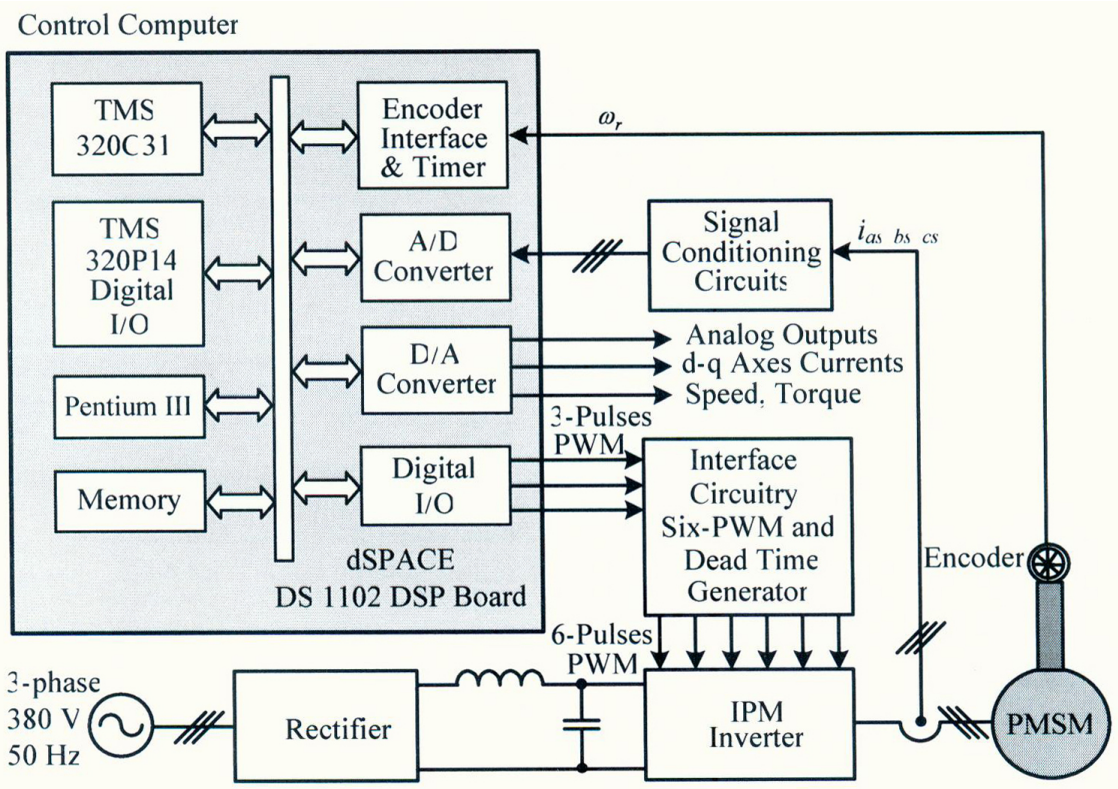

Fig. 4. DSP-based robust wavelet-neural-network sliding-mode control (RWNNSMC) for field-oriented PMSM drive system.

model under the full load condition with a recovery time of $0.22 \mathrm{sec}$ and a maximum dip of $8 \mathrm{rad} / \mathrm{sec}$ while the SMC provides a slower response for the reference model under the full load condition with a longer recovery time of about $0.3 \mathrm{sec}$ and a larger dipping in the rotor speed of about of $12 \mathrm{rad} / \mathrm{sec}$ under the three cases of PMSM uncertainties. Therefore, robust control characteristics under the occurrence of uncertainties can be clearly observed utilizing both of the proposed speed controllers. From Fig. 6, it is evident that a model-following error (MFE) due to the SMC speed controller reaches as much as $\pm 1.4 \mathrm{rad} / \mathrm{sec}$ while the MFE due to the RWNNSMC speed controller is about $\pm 0.45 \mathrm{rad} / \mathrm{sec}$. Also, good model-following tracking responses during all cases of parameter variations are observed from these results. The resulting regulation performances are also much better, in both the speed dip and the recovery time, than those obtained by the SMC speed controller. Therefore, the SMC and RWNNSMC speed controllers are more suitable to control the rotor speed of a PMSM drive system when considering the existence of parameter uncertainties.

\section{B. Experimental results of the addressStreetPMSM Drive Sys- tem}

Some experimental results are provided to further demonstrate the effectiveness of the proposed SMC and RWNNSMC speed controllers for PMSM drive systems. The experimental results of the sliding-mode control and the robust waveletneural-network sliding-mode control due to periodic commands are depicted in Fig. 8. The favorable tracking responses shown in Fig. 8(a) and (b) were obtained by both the SMC and RWNNSMC speed controllers under the occurrence of external disturbances as in the simulations. The experimental results of the speed and model-following error (MFE) responses of the drive system at subsequent loading for both the SMC and RWNNSMC speed controllers are illustrated in Fig. 9.
Moreover, the experimental results of the model-following response, the $\mathrm{q}$-axis current response and the tracking errors of the drive system for both the SMC and RWNNSMC speed controllers are depicted in Fig. 9. Also, the experimental results of the speed response, the load regulation performance and the tracking errors of the drive system for both the SMC and RWNNSMC speed controllers are given in Fig. 10. The experimental results are very close to the simulation results. Comparing the results of RWNNSMC speed controller with the SMC speed controller, the proposed RWNNSMC controller is more suitable for controlling the rotor speed of a PMSM drive system under the possible occurrence of load disturbances and parameter uncertainties.

\section{CONCLUSIONS}

This paper proposed a robust wavelet-neural-network sliding-mode speed controller (RWNNC) for PMSM drive systems under field orientation control which guarantees the robustness in the presence of parameter uncertainties. The proposed robust controllers (SMC and RWNNC) consist of a feed-back SMC in addition to an on-line trained WNNC. Also, this paper successfully demonstrated an application of the SMC and WNNC control systems to control the rotor speed of a field-oriented PMSM drive. The WNNC provides an adaptive control signal based on the error between the reference model and the actual output of the PMSM drive. This error was used to train the connective weights of the WNNC to provide a good model-following response. Therefore, the rotor speed tracking response can be controlled to closely follow the response of the reference model under a wide range of operating conditions. Simulation results have shown that the proposed SMC and RWNNC grant robust model-following tracking responses and good regulation characteristics in the presence of PMSM parameter uncertainties and external load disturbances. Moreover, simulations were carried out using 

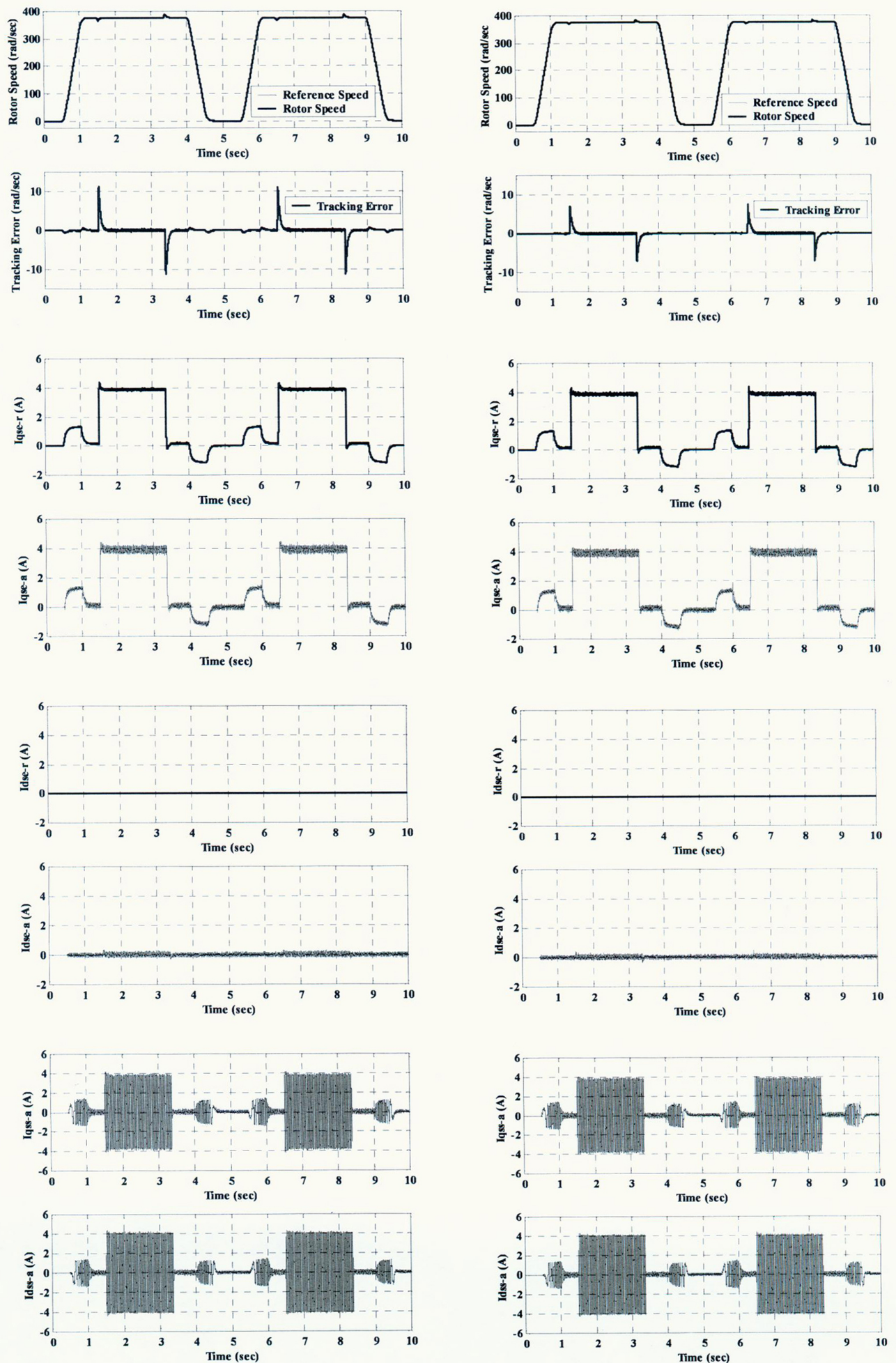

(a) Using SMC speed controller.

(b) Using RWNNSMC speed controller.

Fig. 5. Dynamic response for a reference speed of $377 \mathrm{rad} / \mathrm{sec}$ and subsequent loading of $3.6 \mathrm{~N} . \mathrm{m}$ for both speed controllers. 

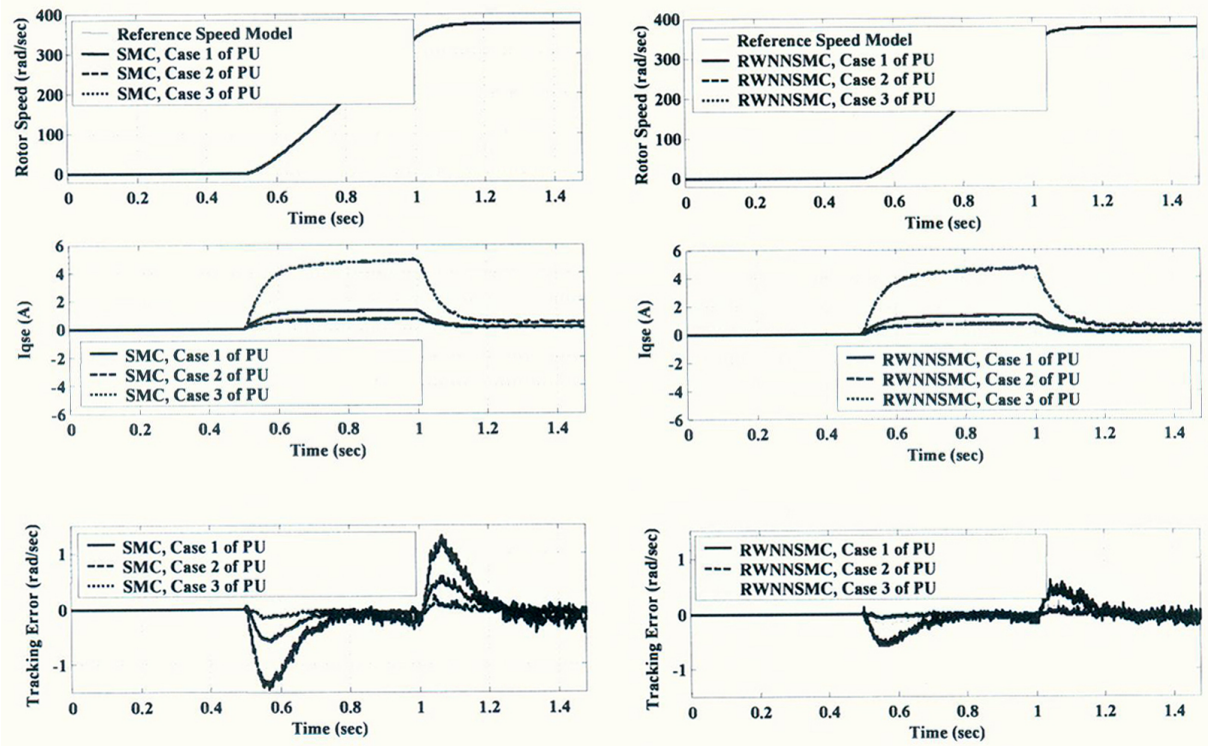

(a) Using SMC speed controller.

(b) Using RWNNSMC speed controller.

Fig. 6. The model following response and tracking errors of the drive system under parameter variations for both speed controllers.
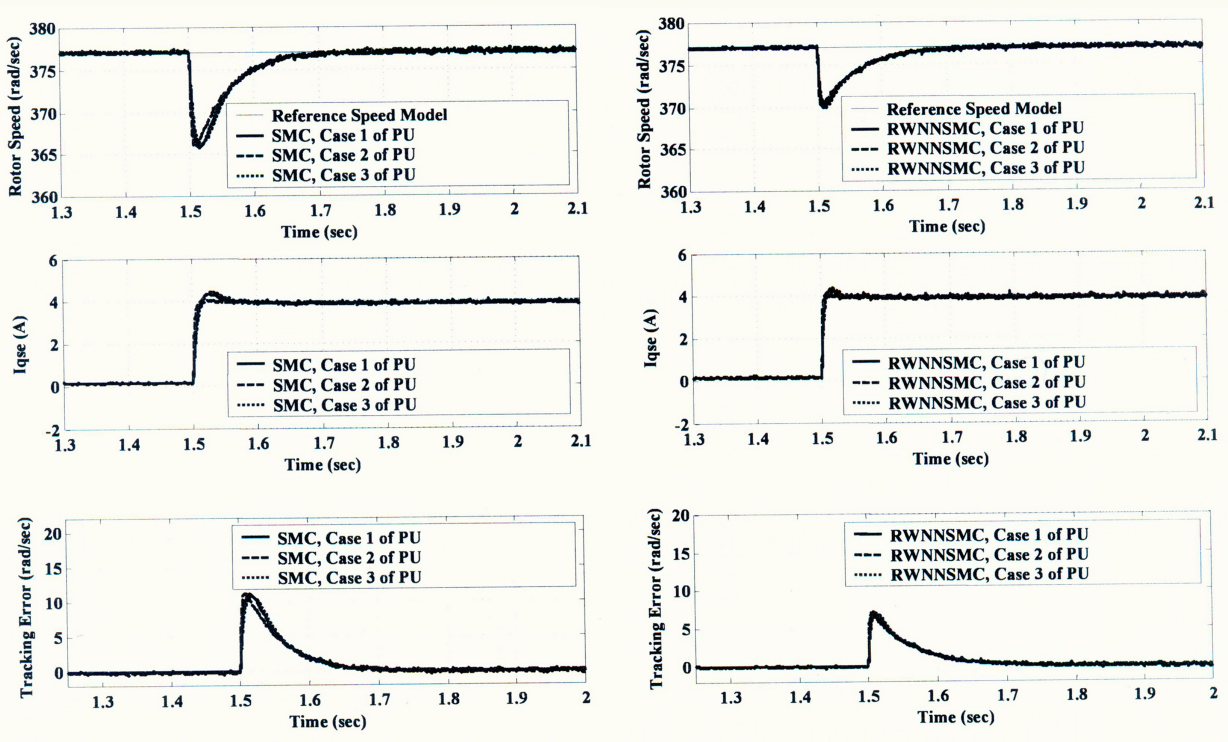

(a) Using SMC speed controller.

(b) Using RWNNSMC speed controller.

Fig. 7. The load regulation performance and tracking errors of the drive system under parameter variations for both speed controllers.

the periodic reference model trajectory to verify the effectiveness of the proposed speed controllers. Finally, the main contributions of this paper are the successful development of the RWNNC system, in which a WNNC is utilized to compensate the uncertainty bound in the SMC system online and the successful application of the proposed RWNNC system methodology to control the rotor speed of a PMSM considering the existence of parameter uncertainties.

\section{APPENDIX}

The PMSM used in this drive system is a three-phase type, $1 \mathrm{hp}, 4$ poles, $208 \mathrm{~V}, 60 \mathrm{~Hz}, 1800 \mathrm{rpm}$, voltage constant: 0.314 $\mathrm{v} . \mathrm{s} / \mathrm{rad}, R_{s}=1.5 \Omega, L_{s s}=0.05 \mathrm{H}, J_{m}=0.003 \mathrm{~kg} . \mathrm{m}^{2}$ and $\beta_{m}=0.0009$ N.m $/ \mathrm{rad} / \mathrm{sec}$.

$$
\begin{gathered}
K_{m}^{\omega}=(P / 2) / J_{m}, K_{t}=(3 P / 4) \lambda_{m}, K_{P I}^{c}=K_{p}^{c} / K_{i}^{c}, \\
\tau_{s}=L_{s} / R_{s}, K_{m}^{c}=K_{i}^{c} / R_{s} \tau_{s}, \tau_{c}=\left(1 / \tau_{s}+K_{p}^{c} / R_{s} \tau_{s}\right), \\
K^{\omega}=\omega_{n}^{4} / K_{m}^{\omega} K_{m}^{c} K_{t} K_{i}^{\omega}, b_{0}=K_{i}^{\omega} K_{m}^{\omega} K_{t}, \tau_{1}=K_{P I}^{c}, \\
b_{1}=\left(\beta_{m} / J_{m}+K_{m}^{\omega} K_{t} K_{p}^{\omega}+b_{0} \tau_{2}\right), \\
b_{2}=\left(1+\tau_{2} \beta_{m} / J_{m}+K_{m}^{\omega} K_{t} K_{d}^{\omega}+K_{m}^{\omega} K_{t} K_{p}^{\omega} \tau_{2}\right),
\end{gathered}
$$



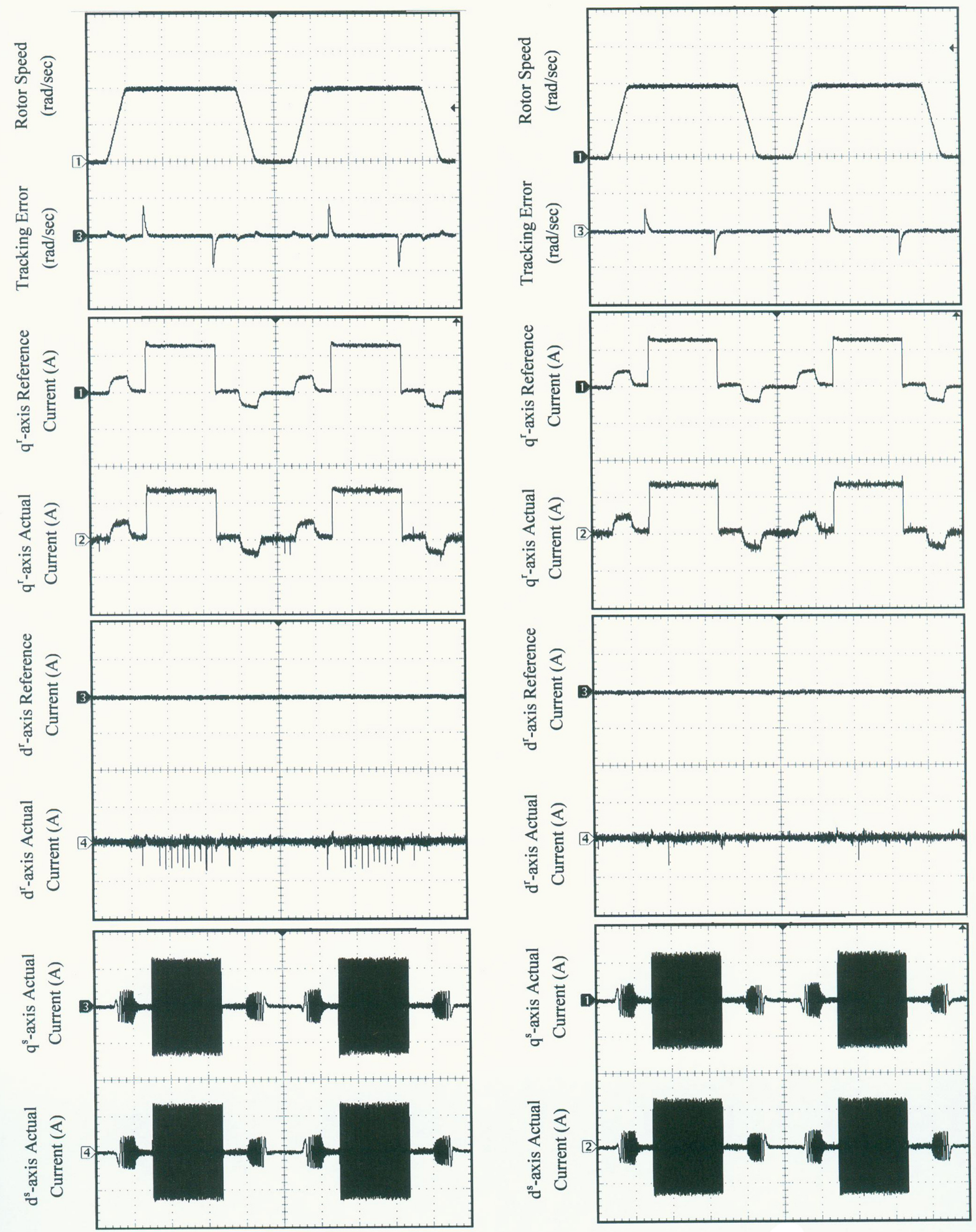

(a) Using SMC speed controller.

(b) Using RWNNSMC speed controller.

Fig. 8. Experimental results of the daynamic response for a reference speed of $377 \mathrm{rad} / \mathrm{sec}$ and subsequent loading of $3.6 \mathrm{~N}$.m for both SMC and RWNNC speed controllers: speed response $189(\mathrm{rad} / \mathrm{sec}) / \mathrm{div}$, tracking error response $15(\mathrm{rad} / \mathrm{sec}) / \mathrm{div}$, torque response $3 \mathrm{~N}$.m/div, d-q-axes current response in the synchronous and stationary frames $3.5 \mathrm{~A} / \mathrm{div}$, time base for all traces $1 \mathrm{sec} / \mathrm{div}$. 


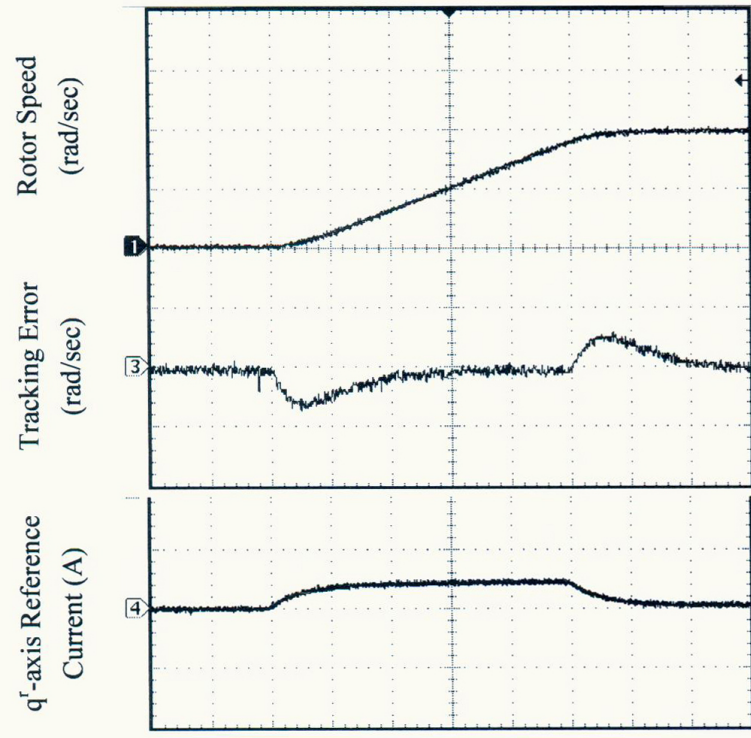

(a) Using SMC speed controller.

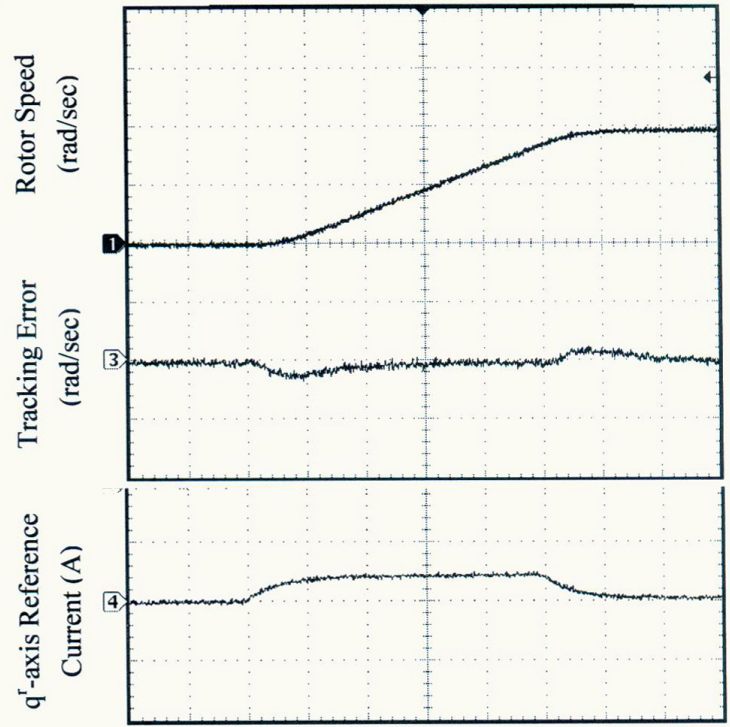

(b) Using RWNNSMC speed controller.

Fig. 9. Experimental results of the model-following response, current response and tracking errors of the drive system for both SMC and RWNNC speed controllers: speed response $189(\mathrm{rad} / \mathrm{sec}) / \mathrm{div}$, model-following error (MFE) $0.65(\mathrm{rad} / \mathrm{sec}) / \mathrm{div}$, q-axis current response in the synchronous frame $3.5 \mathrm{~A} / \mathrm{div}$, time base for all traces $100 \mathrm{msec} / \mathrm{div}$.
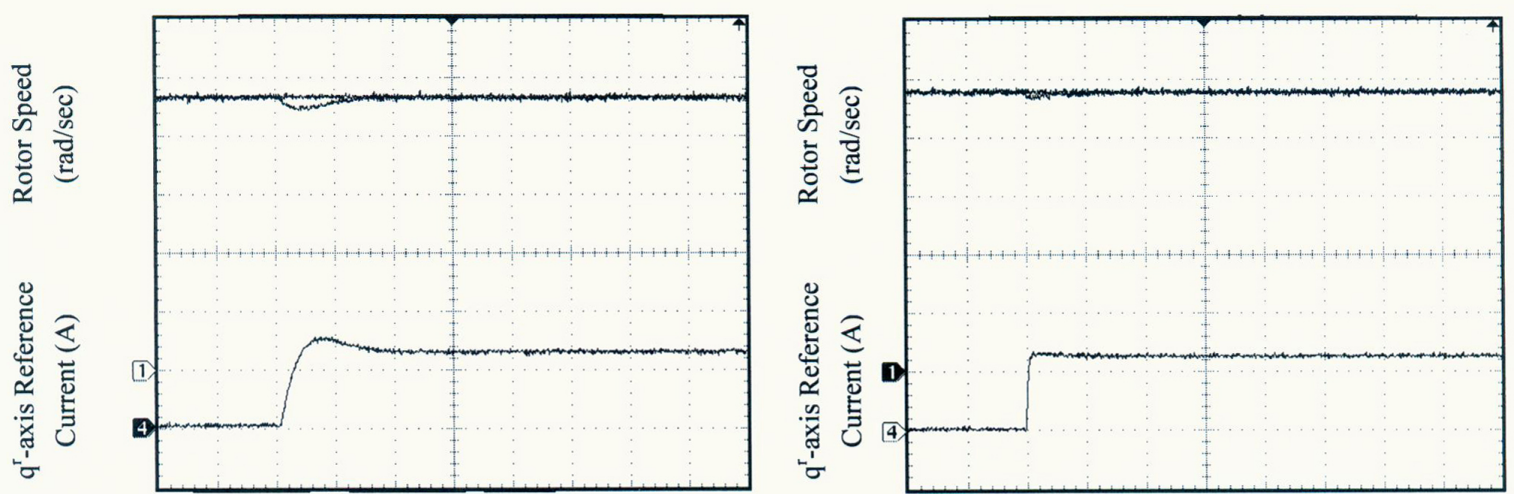

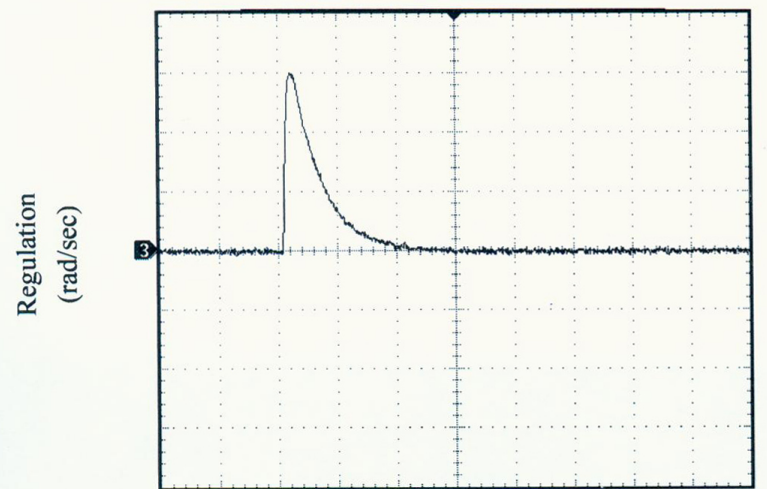

(a) Using SMC speed controller.

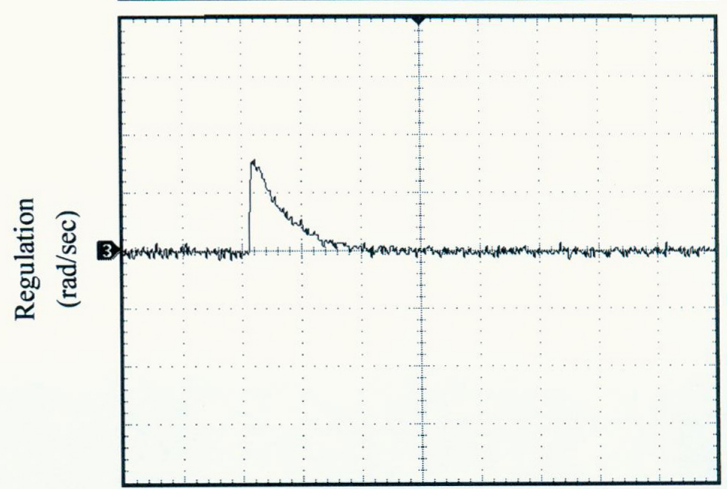

(b) Using RWNNSMC speed controller.

Fig. 10. (Continued) Experimental results of the model-following response, current response and tracking errors of the drive system for both SMC and RWNNC speed controllers: speed response 189 ( $\mathrm{rad} / \mathrm{sec}) / \mathrm{div}$, model-following error (MFE) 0.65 ( $\mathrm{rad} / \mathrm{sec}) / \mathrm{div}$, q-axis current response in the synchronous frame $3.5 \mathrm{~A} / \mathrm{div}$, time base for all traces $100 \mathrm{msec} / \mathrm{div}$. 


$$
\begin{gathered}
b_{3}=\left(\tau_{2}+K_{m}^{\omega} K_{t} K_{d}^{\omega} \tau_{2}\right), K_{p}^{c}=\left(2 \zeta \omega_{n}-1 / \tau_{s}\right) / R_{s} \tau_{s}, \\
K_{i}^{c}=\omega_{n}^{2} R_{s} \tau_{s} .
\end{gathered}
$$

$d^{r}-q^{r} \quad$ rotating reference frame coordinates

$d^{s}-q^{s} \quad$ stationary reference frame coordinates

$e_{\omega}^{m f} \quad$ error signal

$G_{r m}(s) \quad$ transfer function of the reference model

$i_{d s}^{r}, i_{q s}^{r} \quad$ stator currents in $d^{r}-q^{r}$ axis rotating reference

frame

$i_{d s}^{r *} \quad$ reference current in $\mathrm{d}$-axis

$\delta i_{q s}^{r *} \quad$ adaptive control signal

$\delta i_{q s}^{r * W N N C}$ output of the wavelet-neural-network controller

$i_{q s}^{r * S M C} \quad$ output of the sliding-mode controller

$J_{m} \quad$ rotor inertia

$K_{t} \quad$ torque constant

$K_{\omega s} \quad$ control gain

$K_{p s}, K_{d s}, K_{i s} \quad$ positive constants

$K_{p}^{\omega} \quad$ proportional gain of the 2DOF I-PD controller

$K_{i}^{\omega} \quad$ integral gain of the 2DOF I-PD controller

$K_{d}^{\omega} \quad$ derivative gain of the 2DOF I-PD controller

$L(t) \quad$ lumped parameter uncertainty

$L_{s s} \quad$ stator self inductance

$P \quad$ number of poles

$R_{s} \quad$ stator resistance and self inductance of the

$s \quad$ differential operator

$S(t) \quad$ sliding surface

$T_{e} \quad$ electromagnetic torque

$T_{L} \quad$ load torque

$V_{d s}^{r}, V_{q s}^{r} \quad$ stator voltages in $d^{r}-q^{r}$ axis rotating reference frame

$\omega_{r}^{m f} \quad$ output of the reference model in electrical $\mathrm{rad} / \mathrm{sec}$

$\lambda_{m}, \quad$ flux linkage

$\omega_{r} \quad$ rotor speed in electrical $\mathrm{rad} / \mathrm{sec}$

$\beta_{m} \quad$ friction coefficient

$\epsilon \quad$ approximation tracking error

$\eta_{\mu} \quad$ the learning rate parameter of the translation of the mother wavelet

$\eta_{\sigma} \quad$ learning rate parameter of the dilation of the mother wavelet

$\eta_{\omega} \quad$ learning rate parameter of the connecting weights of the output layer of the WNNC reference quantities

\section{REFERENCES}

[1] P.C. Krause, Analysis of Electric Machinery, New York, McGraw Hill, 1986.

[2] B. K. Bose, Modern Power Electronics and AC Drives, Prentice Hall, Upper Saddle River, 2002.

[3] Peter Vas, Vector Control of AC Machines, Oxford: Clarendon Press, 1990.

[4] Ned Mohan, Advanced Electric Drives: Analysis, Control, and Modeling using Simulink, MNPERE Press, USA, 2001.

[5] Lixin Tang and Gui-Jia Su, "High-performance control of two threephase permanent-magnet synchronous machines in an integrated drive for automotive applications," IEEE Transactions on Power Electronics, Vol. 23, No. 6, pp. 3047-3055, Nov. 2008.

[6] Lixin Tang, Gui-Jia Su and Xianghui Huang, "Experimental highperformance control of two permanent magnet synchronous machines in an integrated drive for automotive applications," IEEE Transactions on Power Electronics, Vol. 23, No. 2, pp. 977-984, Mar. 2008.
[7] V. I. Utkin, "Sliding mode control design principles and applications to electric drives," IEEE Transactions on Industrial Electronics, Vol. 40, pp. 23-36, Feb. 1993.

[8] I. C. Baik, K. H. Kim, and M. J. Youn, "Robust nonlinear speed control of PM synchronous motor using adaptive and sliding mode control techniques," Proc. IEE_Elect. Power Application, Vol. 145, No. 4, pp. 369-376, 1998.

[9] Z. H. Akpolat, G. M. Asher, and J. C. Clare, "A practical approach to the design of robust speed controllers for machine drives," IEEE Transactions on Industrial Electronics, Vol. 47, pp. 315-324, Apr. 2000.

[10] S. K. Chung, J. H. Lee, J. S. Ko, and M. J. Youn, "Robust speed control of brushless direct drive motor using integral variable structure control," Proc. IEE-Elect. Power Application, Vol. 142. No. 6, pp. 361-370, 1995.

[11] Franck Betin, Daniel Pinchon, and Gérard-André Capolino, "A timevarying sliding surface for robust position control of a DC motor drive," IEEE Transactions on Industrial Electronics, Vol. 49, No. 2, pp. 462472, Apr. 2002.

[12] Zhuang Xu and M. Faz Rahman, "Direct torque and flux regulation of an IPM synchronous motor drive using variable structure control approach," IEEE Transactions on Power Electronics, Vol. 22, No. 6, pp. 2487-2498, Nov. 2007.

[13] Fayez F. M. El-Sousy, "Robust tracking control based on intelligent sliding-mode model-following position controller for PMSM servo drives," Journal of Power Electronics (JPE), Vol. 7, No. 2, pp. 159173, Apr. 2007.

[14] Fayez F. M. El-Sousy, "An intelligent model-following sliding-mode position controller for PMSM servo drives," 4th IEEE International Conference on Mechatronics (ICM2007), Kumamoto, Japan, May 8-10, 2007.

[15] Fayez F. M. El-Sousy, "AddressStreetA vector-controlled PMSM drive with a continually on-line learning hybrid neural-network modelfollowing speed controller," Journal of Power Electronics (JPE), Vol. 5, No. 2, pp. 197-210, Apr. 2005.

[16] F. J. Lin, W. J. Huang, and R. J. Wai, "A supervisory fuzzy neural network control system for tracking periodic inputs," IEEE Transactions on Fuzzy Systems, Vol. 7, pp. 41-52, Feb. 1999.

[17] Y. S. Lu and J. S. Chen, "A self-organizing fuzzy sliding-mode controller design for a class of nonlinear servo systems," IEEE Transactions on Industrial Electronics, Vol. 41, pp. 492-502, Oct. 1994.

[18] F.-J. Lin and S. L. Chiu, "Adaptive fuzzy sliding-mode control for PM synchronous servo-motor drives," Proc. IEE-Control Theory Applications, Vol. 145, No. 1, pp. 63-72, 1998.

[19] Fayez F. M. El-Sousy, "Intelligent model-following position control for PMSM servo drives," 6th WSEAS International Conference on Neural Networks, Lisbon, Portugal, pp. 230-238, Jun. 16-18, 2005.

[20] Faa-Jeng Lin, and Chih-Hong Lin, "A permanent-magnet synchronous motor servo drive using self-constructing fuzzy neural network controller," IEEE Transactions on Energy Conversion, Vol. 19, No. 1, pp. 66-72, Mar. 2004.

[21] Faa-Jeng Lin, Chih-Hong Lin, and Po-Hung Shen, "Self-constructing fuzzy neural network speed controller for permanent-magnet synchronous motor drive," IEEE Transactions on Fuzzy Systems, Vol. 9, No. 5, pp. 751-759, Oct. 2001.

[22] Y.C Chen and C.C Teng, "A model reference control structure using a fuzzy neural network," IEEE Transaction on Fuzzy Sets and Systems, Vol. 73, pp. 291-312, 1995.

[23] Matlab Simulink User Guide, The Math Work Inc., 1997.

[24] C. M. Ong, "Dynamic Simulation of Electric Machinery Using Matlab and Simulink," Printice Hall, 1998.

[25] Y. C. Pati and P. S. Krishnaprasad, "Analysis and synthesis of feed forward neural networks using discrete affine wavelet transformations," IEEE Transactions on Neural Networks, Vol. 4, pp. 73-85, Jan. 1998.

[26] B. Delyon, A. Juditsky, and A. Benveniste, "Accuracy analysis for wavelet approximations," IEEE Transactions on Neural Networks, Vol. 6, pp. 332-348, Mar. 1995.

[27] C. F. Chen and C. H. Hsiao, "Wavelet approach to optimising dynamic systems," Proc. IEE—Control Theory Applications, Vol. 146, no. 2, pp. 213-219, 1999.

[28] T. Lindblad and J. M. Kinser, "Inherent features of wavelets and pulse coupled networks," IEEE Transactions on Neural Networks, Vol. 10, pp. 607-614, May 1999.

[29] Q. Zhang and A. Benveniste, "Wavelet networks," IEEE Transactions on Neural Networks, Vol. 3, pp. 889-898, Nov. 1992.

[30] J. Zhang, G. G. Walter, Y. Miao, and W. N. W. Lee, "Wavelet neural networks for function learning," IEEE Transactions on Signal Processing, Vol. 43, pp. 1485-1496, Jun. 1995. 
[31] Q. Zhang, "Using wavelet network in nonparametric estimation," IEEE Transactions on Neural Networks, Vol. 8, pp. 227-236, Mar. 1997.

[32] L. M. Reyneri, "Unification of neural and wavelet networks and fuzzy systems," IEEE Transactions on Neural Networks, Vol. 10, pp. 801-814, Jul. 1999.

[33] Z. Zhang and C. Zhao, "A fast learning algorithm for wavelet network and its application in control," IEEE International Conference on Control and Automation, pp. 1403-1407, Chain, May 30- Jun. 1, 2007.

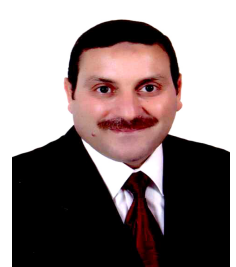

Fayez F. M. El-Sousy was born in Gahrbia Prefecture, Egypt in 1965. He received his B.S. in Electrical Power and Machines Engineering from Menoufia University, Egypt, in 1988, and his M.S. and Ph.D. in Electrical Power and Machines Engineering from Cairo University, Egypt, in 1994 and 2000, respectively. Since 1990, he has been with the Department of Power Electronics and Energy Conversion at the Electronics Research
Institute (ERI), Egypt where he is currently an Associate Professor. From April 2004 to October 2004, he was a Post Doctoral Visiting Researcher at Kyushu University, Graduate School of Information Science and Electrical Engineering, Energy Conversion Laboratory, Japan. From 2007 to 2009, he was with the department of Electrical Engineering, College of Engineering at Al-Kharj, King Saud University, Saudi Arabia. He was also the Chairman of the Department of Electrical Engineering. From 2009 till now, he has been with the department of Electrical Engineering, College of Engineering, Al-Kharj University, Saudi Arabia. He is also the Chairman of the Department of Electrical Engineering. His research interests are in the areas of modeling and control of motor drives, LIM and PMLSM drives, motion-control systems, wind energy systems, intelligent control, optimal control, power electronics, and the control of linear motor Maglev vehicle drive systems. Dr. El-Sousy is currently interested in the hybrid control of two-axis motion control systems. 